\title{
Effect of Titanium Oxide Nanoparticle Additives on R22 Refrigeration System
}

\author{
A. Senthilkumar, N. Shivakumar, Muhamed Razi, Basil, Mohammed Sheeth
}

\begin{abstract}
To explore the conservation technique for energy resources and making more efficient new energy systems has initi ated the demand for usage

of Nanoparticle in heat transfer fluids. The study explored the impact of Nanolubricants based on Mineral refrigeration oil and $\mathrm{Tio}_{2}$ Nanoparticle at three various mass concentrations $0.6 \mathrm{~g} / \mathrm{l}, 024 \mathrm{~g} / \mathrm{l}$ and $046 \mathrm{~g} / \mathrm{l}$ in a vapour confining refrigeration system. Experiments are finalized out to read the important functions of cooling models, like as coefficient of performance (C.O.P), Compressor work and refrigeration effect when titanium oxide (Tio 2$)$ Nanoparticle are added to the lubricant. The experiment conduced using R22 refrigerant. The process of $\mathrm{Tio}_{2}$ Nanoparticle by the cooling model was raising the cooling level of accuracy and Collaborative of task and reduction of compressor work.
\end{abstract}

Keywords: Nanolubricants, $\mathrm{Tio}_{2} \quad$ Nanoparticle, R22, Coefficient of performance.

\section{INTRODUCTION}

Vapour confining periods are placed for practically in all kinds of cooling environments .some of the features in this model are based on local, economic and automated operations.Because of the widespread use of these heat pumps refrigeration systems they process a huge worldwide constr ain for power.In this view, the dispersion ofnanoparticles in comon coating oil as a Nanolubricant is a new way of devel oping the adaptability of cooling scheme.

With the rapid development in nanotechnology, the metals and metal oxides are available in Nano sizes i.e. in the form of powders and which lead to nanofluids.Nanofluids are measured to dispersing Nano sized molecule. (1-100 nm) in

Revised Manuscript Received on December 30, 2019.

* Correspondence Author

A.Senthilkumar, Assistant Professor Mechanical Department, AarupadaiVeedu Institute Of Technology, Vinayaka Mission's Research Foundation, Chennai, India. Email: xyz1@blueeyesintlligence.org

N.Shivakumar, Assistant Professor Mechanical Department, AarupadaiVeedu Institute Of Technology, Vinayaka Mission's Research Foundation, Chennai, India. Email: xyz1@blueeyesintlligence.org

Muhamed razi, UG Student, Mechanical Department, Aarupadai Veedu

Institute Of Technology, Vinayaka Mission's Research Foundation, Chennai, India. Email: xyz1@blueeyesintlligence.org

Mohamed basil, UG Student, Mechanical Department, Aarupadai Veedu Institute Of Technology, Vinayaka Mission's Research Foundation, Chennai, India. Email: xyz1@blueeyesintlligence.org

Mohammed sheeth, UG Student, Mechanical Department, Aarupadai Veedu Institute Of Technology, Vinayaka Mission's Research Foundation, Chennai, India. Email: xyz1@blueeyesintlligence.org

(C) The Authors. Published by Blue Eyes Intelligence Engineering and Sciences Publication (BEIESP). This is an open access article under the CC BY-NC-ND license (http://creativecommons.org/licenses/by-nc-nd/4.0/) traditional fluids and have greater thermal potential when correlated with base fluids. [1] This research analyzed the system performance of a heat pump as a refrigerant using $\mathrm{TiO} 2$ and R22 (5wt percent). Finally while mixing $\mathrm{TiO} 2$ which is Nanoparticle marginally reduces the COP , the Nano fluid will significantly raises the heating cycle from the COP, primarily due to raised compression energy utilization. A simple method was employed to identify the role of Nano particles in lubrication using disk on disk tester. The friction coefficient of the sample is reduced appreciably [2]. There was an attempt to research and describe the methods of Nano diamond molecules, while further added to lubrication of mineral oil and was noticed a pair of common resistance coefficient and wear got reduced by the addition of nanodiamond particles.0.01\%weight concentration improved the triobological performance [3].The diamond Nanoparticle used for research and are mixed in various concentrations ranging from 0 to 0.8 wt percent. The results obtained showed that PAO oil has a minimum friction coefficient (COF) which contains 0.2 wt percent diamond Nano particles [4].A Nanolubricants containing diamond Nanoparticle was mingled with R134a at three various mass concentrations at a volume fraction of 2.6 percent with a polyolester lubricant. In one occasion the diamond Nanoparticle increases the heat transmission correlated to heat transmission of pure R134a model by an average of 98 percent [5].

The results obtained from the experiment suggested that boiling heat transfer coefficient of R113/oil combination containing diamond Nanoparticle is greater than 63.4 percent of R113/oil combination without Nanoparticle. In the boiling heat transfer, the enhancement effect of diamond Nanoparticle / oil suspension is greater than that of $\mathrm{CuO}$ Nanoparticle / oil suspension [6]. By using 0.1 percent mass fraction of titanium oxide Nanoparticle in R134a refrigeration system with mineral oil consumed 26.1 percent energy correlated to HFC134a and polyolester oil refrigeration system[7].It is concluded from the experiment that freezing capacity is higher, POE oil is reinstated by a mixture containing nutrient oil and the energy utilization is decreased by $25 \%$ [8].By adding $0.2 \%$ volume of $\mathrm{Al}_{2} \mathrm{O}_{3}$ Nanoparticle the system performance was improved and $10.32 \%$ less energy consumed with R134a working fluid [9]. The titanium oxide Nanolubricants system evaporator air temperature was moderately low compared pure lubricant system without Nanoparticle and compressor power input was very low with both Nanolubricants [10].

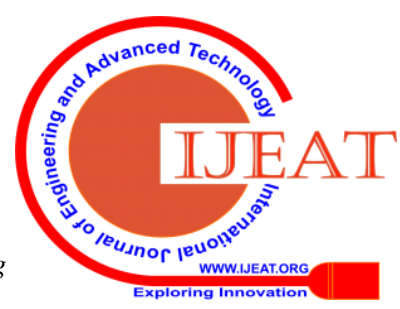




\section{PROPOSED SYSTEMS AND MATERIALS USED}

\section{A .Nanolubricants Preparation}

The suspension of Nanoparticle and compressor oil is termed as Nanolubricants. In this experiment the Nanolubricants was prepared using two-step method. For the preparation of Nanolubricants the titanium oxide Nanoparticle mixed in correct proportion and the stability of the particles also maintained. A titanium oxide Nanoparticle was mixed with Mineral oil with the help of a magnetic stirrer for the $1 \mathrm{hr}$ time duration. After that Nanoparticle dispersed continuously in ultrasonic bath vibrator which produces ultrasonic pulses of $230 \mathrm{~V}$ at $50 \pm 3 \mathrm{kHz}$ carried out by the period of two hour. $\mathrm{UV}$-Vis spectrophotometer is used for signification and to make sure that Nanoparticle are mixed in proper condition with less sediments. The solicitors breaks down the lustration and protect the Nanoparticle with strong circulate into the base solution. The three different volume concentrations of $0.2 \%, 0.4 \%$ and $0.6 \%$ of Nanolubricants was arranged and used in this model.

\section{B. Stability of Nanolubricants}

The stabilization of Nanolubricants and for reduction of agglomerate size the ultrasonic bath was employed. Stability assessment of composite Nanolubricant specimens was tested at room temperature with UV-Vis spectrophotom eter which governs the peak wavelength for absorption of samples used. The colloidal stability of the Nanolubricant dispersions was then calculated by adjusting the sample's sonication time in hours (0.0 h, 0.5 h, 1.0 h, $1.5 \mathrm{~h}$ and $2.0 \mathrm{~h}$ )

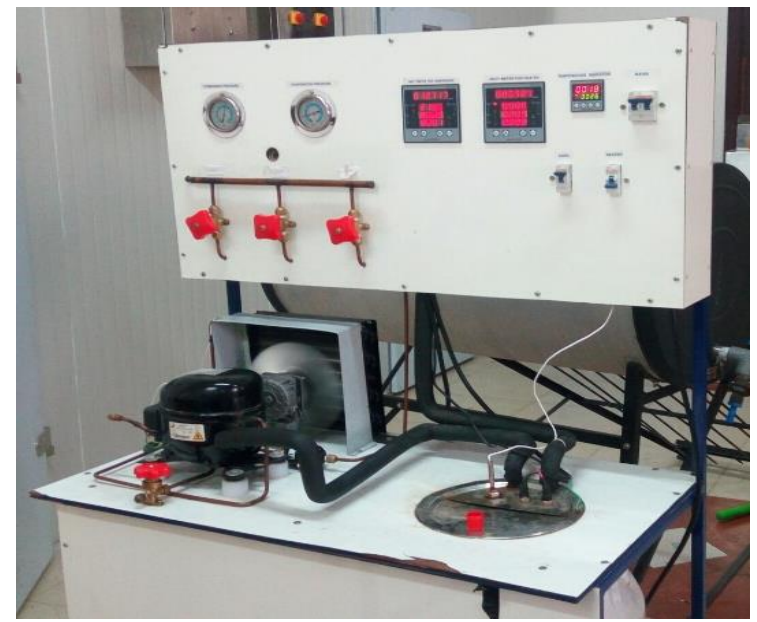

Fig. 1: Experimental Test Rig

The experiment was carried out in vapour compression refrigeration test rig as on Fig 1 and it consists of components like evaporator, air-cooled condenser, compressor and capillary tube. The heat flux was supplied to evaporator by heater $(230 \mathrm{~W})$ and automatic stirrer to continuously stir the water. The power used by the compressor and the heater was measured using energy meter. The heater power regulator adjusts constant heat flux and maintained steady state condition. The compressor was loaded up with the Nanolubricants and the refrigerant R134a. Each time the framework was permitted to balance out for 20 mints.

\section{RESULT AND DISCUSSION}

For experimental analysis, four cases have been considered. The compressor contains Nano lubricants. For the graphical representation i) pure mineral oil ii) Mineral oil and $0.2 \mathrm{~g} / \mathrm{L}$ $\mathrm{TiO}_{2}$ iii) Mineral oil and $0.4 \mathrm{~g} / \mathrm{L} \mathrm{Tio}_{2}$ iv) Mineral oil and $0.6 \mathrm{~g} / \mathrm{L} \mathrm{Tio} 2$.

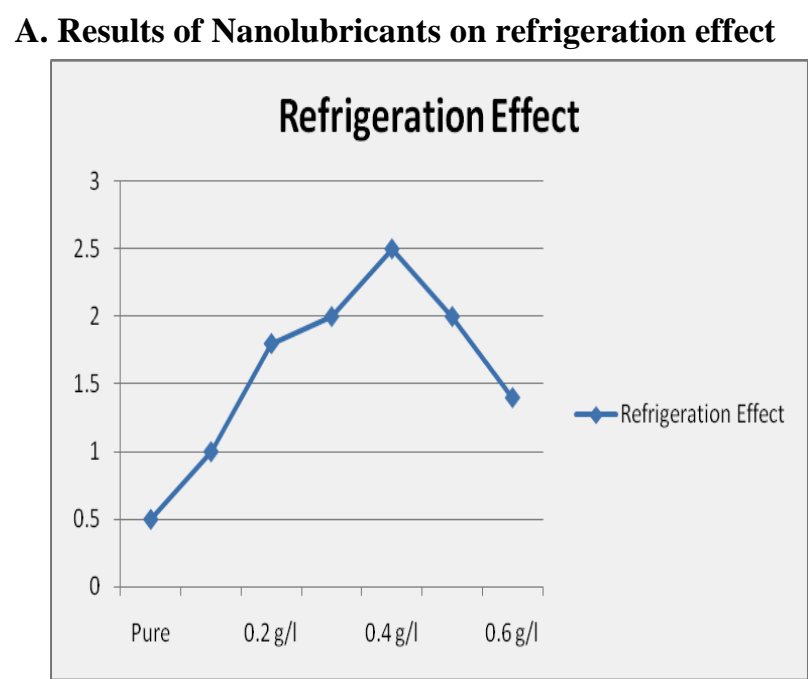

Fig.2: Effect of Nanoparticle on refrigeration effect

It is clear from the above Fig 2 refrigeration effect of $0.2 \mathrm{~g} / \mathrm{l}$ $\mathrm{Tio}_{2}$ is higher compared to other three cases .Time consumed to lower the temperature of cooling load from $20^{\circ} \mathrm{C}$ to $5^{\circ} \mathrm{C}$ is 30 minutes. Time consumed by the pure mineral oil is 50 minutes .I t takes 40 mints for $0.4 \mathrm{~g} / \mathrm{l}$ of Tio 2 and $35 \mathrm{mins} 0.6 \mathrm{~g} / \mathrm{l}$ of $\mathrm{Tio}_{2}$ respectively.

\section{B. Results of Results of Nanolubricants on Compressor} work

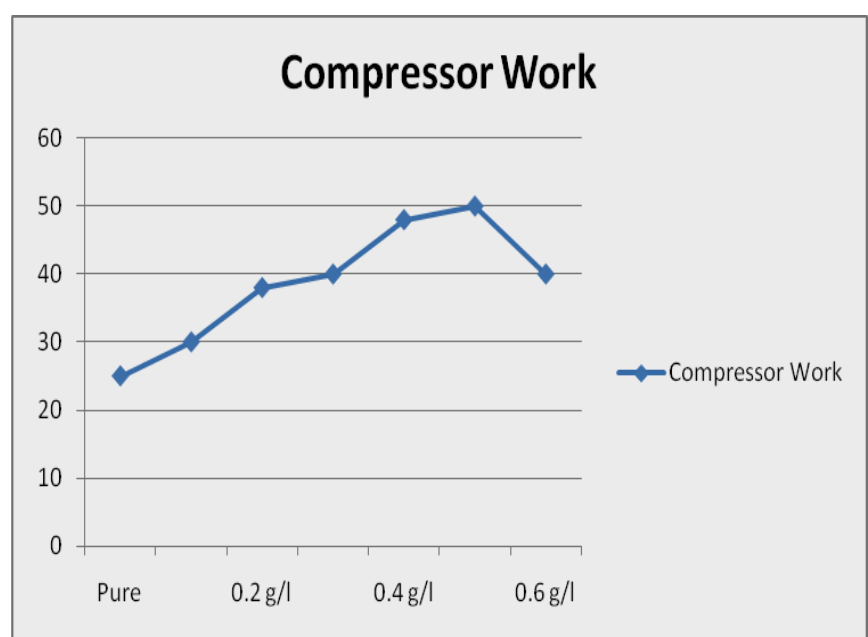

Fig. 3: Issue of Nanoparticle on compressor work

The above Fig 3 displays fall in the compressor work in the freezing system. Compressor work is low with pure refrigerants without Nano lubricants when compared with the other cases. The compressor work is least for pure mineral oil when compared to other Nanolubricants

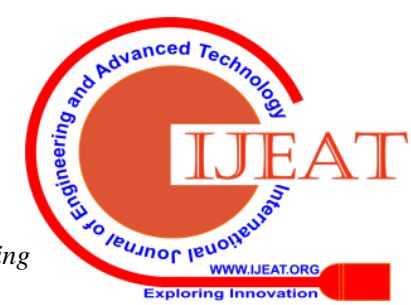


C. Results of Nanolubricants on Coefficient of Performance (COP)

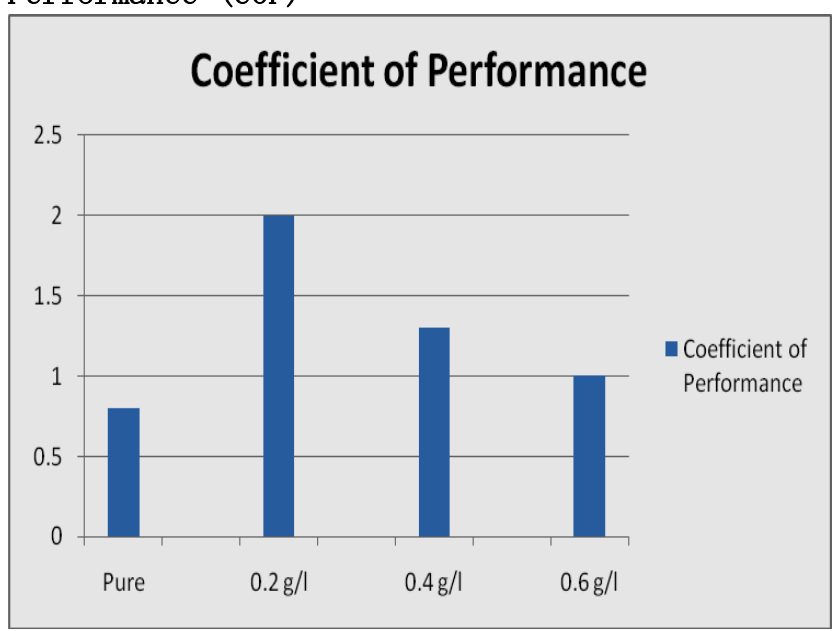

Fig 4: Issue of Nanoparticle on COP

The coefficient of performance (COP) has showed in the Fig 4.The calculation shows the analyzed data..The uses of power input and cooling load was measured by COP. It is seen fine from the figure that the mineral oil $+0.2 \mathrm{~g} / \mathrm{l}$ of $\mathrm{Tio}_{2}$ Nano particles mixture has the large COP while correlate with the other views. The benefit of having lubricant is complex.. When the turn raised the volume of COP, alternate chilling of Nano refrigerant in the condenser and compressor of power utilization is reduced.

\section{CONCLUSION}

A conclusive result of R134a cooling model was evaluated by the help of $\mathrm{TiO}_{2}$ model at three various Nanolubricants of $0.6 \mathrm{~g} / \mathrm{l}, 0.2 \mathrm{~g} / \mathrm{l} \& 0.4 \mathrm{~g} / \mathrm{l}$ was achieved. Refrigeration effect was higher $0.2 \mathrm{~g} / \mathrm{T} \mathrm{Tio}_{2}$ Nanolubricants . The compressor work was maximum. while using $0.2 \mathrm{~g} / \mathrm{Tio}_{2}$ Nanolubricants when compared to other mass concentrations. Finally the Coefficient of performance (COP) was raised by using $0.2 \mathrm{~g} / \mathrm{l}$ $\mathrm{Tio}_{2}$ Nanolubricants.

\section{REFERENCES}

1. Hailong Lia,Wenyan Yangb,Zhixin Yuc,Li Zhao "The performance of a heat pump using nanofluid (R22+TiO2) as the working fluid" - An experimental study Energy Procedia.75 ( 2015 ) 1838 - 1843.

2. Lee, K., Hwang, Y., Cheong, S., Choi, Y., Kwon, L., Lee, J., \& Kim, H. S. (2009). "Understanding the role of nanoparticles in nano-oil lubrication. "Tribology Letters, 35(2), 127-131.

3. Marko, M., Kyle, J., Branson, B., \& Terrell, E. (2014).’Tribological Improvements of Dispersed Nanodiamond Additives in Lubricating Mineral Oil". Journal of Tribology, 137(1).

4. Raina, A., \& Anand, A. (2018). "Lubrication performance of synthetic oil mixed with diamond nanoparticles : Effect of concentration. Materials “Today: Proceedings, 20588- 20594.

5. Kedzierski, M. A. (2012).” Effect of Diamond Nanolubricant on R134a Pool Boiling Heat Transfer. "Journal of Heat Transfer, 134.

6. Peng, H., Ding, G., Hu, H., Jang, W., Zhuang, D., \& Wang, K. (2010). "Nucleate pool boiling heat transfer characteristics of refrigerant/oil mixture with diamond nanoparticles". International Journal of Refrigeration(33), 347-358.

7. Bi,S.-s.,Shi,L.\&Zhang, L.-l. (2008).” Application of nanoparticles in domestic refrigerators". Applied Thermal Engineering, 28(14-15), 1834-1843.

8. Subramani, N., \& Prakash, M. J. (2011). "Experimental studies on a vapour compression system using nanorefrigerants". International Journal of Engineering, Science and Technology, 3(9), 95-102.

9. Kumar, S. D., \& Elansezhian, R. (2012).” Experimental Study on Al2O3-R134a Nano Refrigerant in Refrigeration System" International Journal of Modern Engineering Research (IJMER), 2(5), 3927-3929.
10. Adelekan,DS.,Ohunakin,O.S.,Badarinde,T.O.,Odunfa,M.K.,Leramo,R. O.,Oyedepo,S.O.,\&Badejo,D.O.(2017). "Experimental performance of LPG refrigerant charges with varied concentration of $\mathrm{TiO} 2$ nano-lubricants in a domestic refrigerator."Case Studies in Thermal Engineering, 55-61.

\section{AUTHORS PROFILE}

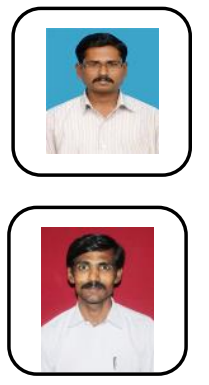

A.Senthilkumar*, Assistant Professor Mechanical Department, AarupadaiVeedu Institute Of Technology, Vinayaka Mission's Research Foundation, Deemed To Be University. Having 11 years of experience.

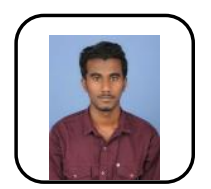

N.Shivakumar, Assistant Professor Mechanical Department, AarupadaiVeedu Institute Of Technology, Vinayaka Mission's Research Foundation, Deemed To Be University. Having 15 years of experience.

Muhamed razi, UG Student, Mechanical Department, Aarupadai Veedu Institute Of Technology, Vinayaka Mission's Research Foundation, Deemed To Be University.

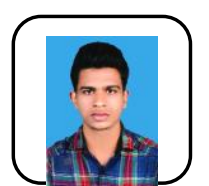

Mohamed basil, UG Student, Mechanical Department, Aarupadai Veedu Institute Of Technology, Vinayaka Mission's Research Foundation, Deemed To Be University.

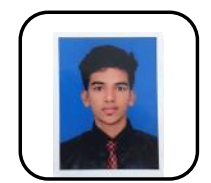

Mohammed sheeth, UG Student, Mechanical Department, Aarupadai Veedu Institute Of Technology, Vinayaka Mission's Research Foundation, Deemed To Be University. 